CODEN: BAMOAD

VOLUME 81

NUMBER 6
PAGES 961-1162

NOVEMBER 1975

ISSUE 759

\title{
BULLETIN \\ of the
}

American Mathematical Society

\author{
Edited by \\ PAUL R. HALMOS JOHN L. KELLEY \\ HANS F. WEINBERGER
}

Published by the

American Mathematical Society

PROVIDENCE, RHOdE ISLAND 


\title{
AMERICAN MATHEMATICAL SOCIETY
}

\author{
Business Office: P.O. Box 6248, Providence, Rhode Island 02940
}

Gordon L. Walker, Executive Director

Lincoln K. Surst, Deputy Director

\section{OFFICERS}

President: Lipman Bers, Dept. of Mathematics, Columbia University, New York, NY 10027

Past-President: Saunders Mac Lane, Dept. of Mathematics, Eckhart Hall, University of Chicago, Chicago, IL 60637

Vice-Presidents: Raoul H. Bott, Dept. of Mathematics, Harvard University, Cambridge, MA 02138; Irving Kaplansky, Dept. of Mathematics, University of Chicago, Chicago, IL 60637; John W. Milnor, School of Mathematics, Institute for Advanced Study, Princeton, NJ 08540

Secretary: Everett Pitcher, Dept. of Mathematics, Lehigh University, Bethlehem, PA 18015

Associate Secretaries: Paul T. Bateman, Dept. of Mathematics, University of Illinois, Urbana, IL 61801; Walter H. Gottschalk, Dept. of Mathematics, Wesleyan University, Middletown, CT 06457; Orville G. Harrold, Jr., Dept of Mathematics, Florida State University, Tallahassee, FL 32306; Kenneth A. Ross, Dept. of Mathematics, University of Oregon, Eugene, OR 97403

Treasurer: Franklin P. Peterson, Dept of Mathematics, Massachusetts Institute of Technology, Cambridge, MA 02139

Associate Treasurer: Murray H. Protter, Dept. of Mathematics, University of California, Berkeley, CA 94720

Board of Trustees: Paul T. Bateman, Dept. of Mathematics, University of Illinois, Urbana, IL 61801; Lipman Bers (ex officio); Calvin C. Moore, Dept. of Mathematics, University of California, Berkeley, CA 94720; Richard S. Palais, Dept. of Mathematics, Brandeis University, Waltham, MA 02154; Franklin P. Peterson (ex officio); Murray H. Protter (ex officio); Alex Rosenberg, Dept. of Mathematics, Cornell University, Ithaca, NY 14850; Abraham H. Taub, Dept. of Mathematics, University of California, Berkeley, CA 94720 Council Members: See inside back cover.

\section{DUES}

For ordinary members whose annual professional income is below $\$ 15,000$. the dues are $\$ 24$; for those whose professional income is $\$ 15,000$ or more, the dues are $\$ 32$. Dues are payable to the Ameriean Mathematical Society, P.O. Box 1571, Annex Station, Providence, RI 02901.

\section{INFORMATION FOR SUBSCRIBERS}

Subscription prices for Volume 81 (1975) are list $\$ 18.00$, member $\$ 9.00$. Subscription prices for Volume 82 (1976) are list $\$ 22,00$, member $\$ 11.00$. The subscription price for members is included in the annual dues. Back number prices per volume for Volumes 1-55 (1894-1949) are list $\$ 28.00$, member $\$ 21.00$; Volumes 56-80 (1950-1974), list $\$ 21.00$, member $\$ 15.75$. Volume 81 (1975) as a back volume will be list $\$ 27,00$, member $\$ 20.25$.

Back volumes of the BULLETIN are also available on $16 \mathrm{~mm}$ microfilm, either negative or positive, and may be mounted either on spools or in Eastman or 3M cartridges. Volumes 1-80 (1894-1974) are mounted on 15 spools and cost $\$ 595.00$ for spools or $\$ 640.00$ for cartridges. Only current subscribers are eligible to purchase back volumes on microfilm.

The Bulletin of The American Mathematical Society is published bimonthly in January, March, May, July, September and November. Subseriptions and orders should be addressed to American Mathematical Society, P.O. Box 1571, Annex Station, Providence, RI 02901. All orders must be accompanied by payment. Other correspondence should be addressed to P.O. Box 6248, Providence, RI 02940.

Second-class postage paid at Providence, Rhode Island and additional mailing offices. 